\title{
Electrophysiological effects of mexiletine in $\operatorname{man}^{1}$
}

\author{
Julius C. Roos, Adolf C. A. Paalman, and Arend J. Dunning \\ From the Section of Cardiology, Department of Medicine, and the Laboratory for Clinical Pharmacy and \\ Toxicology, University Hospital Binnengasthuis, Amsterdam, The Netherlands
}

The electrophysiological effects of intravenous mexiletine in a dose of 200 to $250 \mathrm{mg}$ given over 5 minutes, followed by continuous infusion of 60 to $90 \mathrm{mg}$ per hour, were studied in 5 patients with normal conduction and in 20 patients with a variety of disturbances of impulse formation and conduction, by means of His bundle electrography, atrial pacing, and the extrastimulus method. In all but 2 patients the plasma level was above the lower therapeutic limit. Mexiletine had no consistent effects on sinus frequency and atrial refractoriness. The sinoatrial recovery time changed inconsistently in both directions; hoveever, of the 5 patients in whom an increase was evident, 3 had sinus node dysfunction. In most patients mexiletine increased the $A V$ nodal conduction time at paced atrial rates and shifted the Wenckebach point to a lower atrial rate. The effective refractory period of the $A V$ node was not consistently influenced, while the functional refractory period increased in 12 out of 14 patients. The HV intervals increased by a mean of $11 \mathrm{~ms}$ in 8 patients and were unchanged in 17. Both the relative and effective refractory period of the His-Purkinje system increased after mexiletine. Non-cardiac side effects occurred in 7 out of 25 patients, and cardiac side effects, including one serious, in 2.

The results indicate that mexiletine shares some electrophysiological properties with procainamide and quinidine, when given to patients with conduction defects, and that the drug should not be used in patients with pre-existing impairment of impulse formation or conduction. It has additional effects on $A V$ nodal conduction which may be of value in the treatment of re-entrant tachycardias involving the AV node.

Mexiletine (Kö 1173, 1-(2',6'-dimethyl-phenoxy)2aminopropane) is a new antiarrhythmic drug. Its chemical structure and its local anaesthetic properties closely resemble those of lignocaine. It has a strong antiarrhythmic effect in the experimental animal (Allen et al., 1972; Singh and Williams, 1972) and in man (Campbell et al., 1973; Talbot et al., 1973; Talbot, 1975; Campbell et al., 1975). Its clinical interest is based on its effectiveness in lignocaine-resistant arrhythmias (Campbell et al., 1973), its strong antiarrhythmic potency in ouabaininduced arrhythmias in animals (Singh and Williams, 1972) and the feasibility of oral administration (Campbell et al., 1973; Talbot et al., 1973; Campbell et al., 1975; Achuff et al., 1975).

The purpose of this study is to analyse the electrophysiological effects of mexiletine on human

Received 26 April 1976.

1Part of this work was presented at the Symposium 'Mexitil in Ventricular Arrhythmias' held in Malta, 7 to 9 April 1976; an abstract of this will be published in Postgraduate Medical fournal. cardiac impulse formation and conduction by means of intracardiac electrocardiography.

\section{Subjects and methods}

Twenty-five patients were studied after informed consent had been obtained. Five patients (group A) had entirely normal impulse conduction, 13 patients (group B) had conduction defects in or distal to the His bundle, while in 7 patients (group C) conduction was delayed above the level of the His bundle.

Sinus node dysfunction was the major defect in 10 patients and 3 patients had complete heart block at the time of study. Four patients were studied within 72 hours of the onset of symptoms of acute myocardial infarction. The relevant clinical data are listed in Table 1. No patient was on digitalis treatment and other antiarrhythmic drugs were withheld for at least 24 hours before the time of study.

The study was performed after a light meal; most of the patients received 10 to $20 \mathrm{mg}$ diazepam orally 30 minutes before catheterization. 
TABLE 1 Clinical data

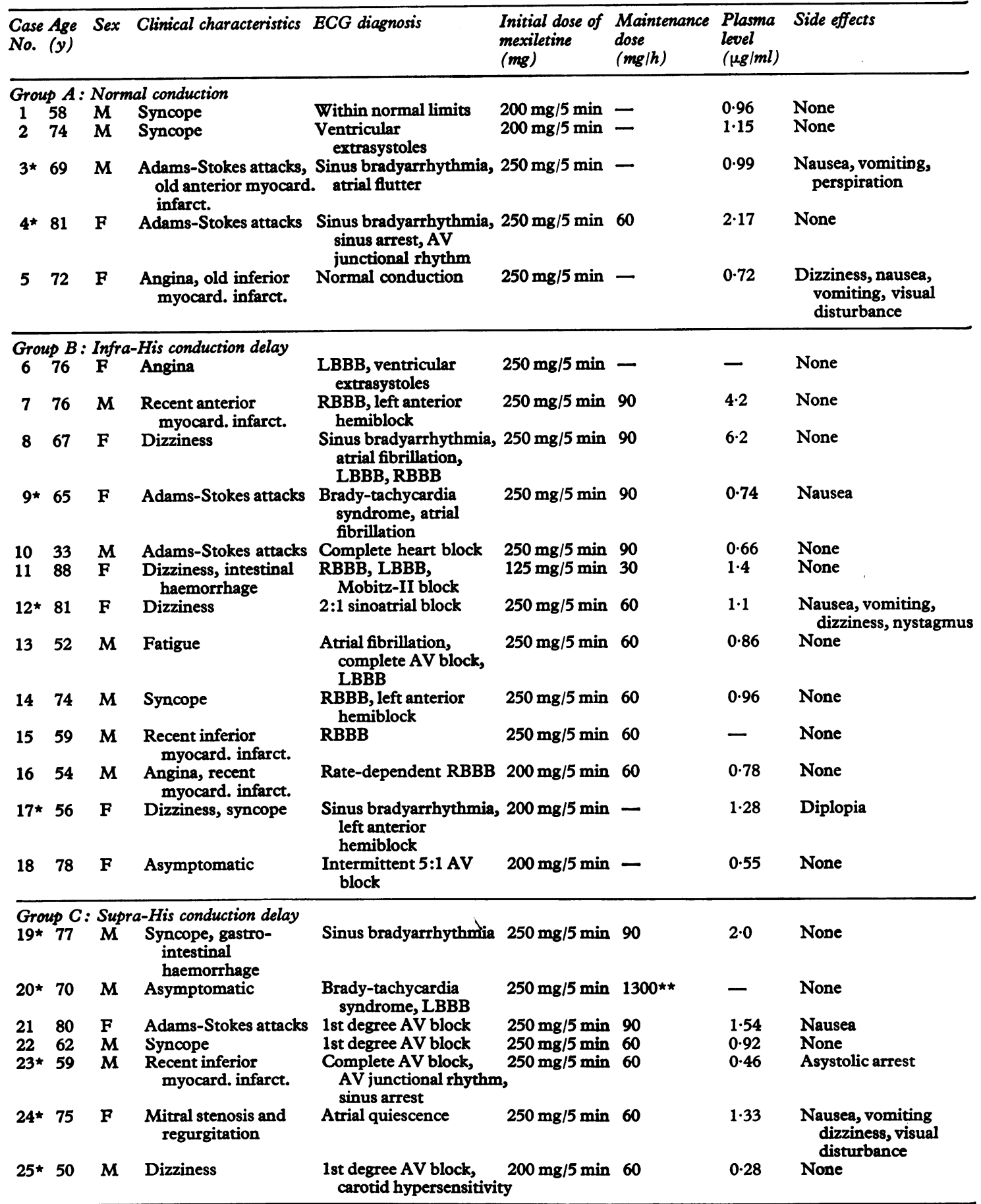

LBBB, left bundle-branch block; RBBB, right bundle-branch block.

*, patients with the sick sinus syndrome.

$\star \star$, this patient accidentally received an additional $250 \mathrm{mg}$ mexiletine in 11 minutes instead of the usual maintenance infusion. 
After local analgesia with $100 \mathrm{mg}$ lignocaine, two electrode catheters were introduced into the right femoral vein. A tripolar electrode wire was positioned against the high lateral wall of the right atrium. The two distal electrodes were used for bipolar atrial pacing, the proximal electrode for the recording of a unipolar high right atrial electrogram.

Another tripolar electrode wire, with electrodes $10 \mathrm{~mm}$ apart, was positioned across the tricuspid valve in the His bundle region, as described by Scherlag et al. (1969). Standard leads I, II, III, a unipolar high right atrial electrogram, and a $\mathrm{His}$ bundle electrogram were recorded on an 8-channel
Elema recorder at a paper speed of $100 \mathrm{~mm} / \mathrm{s}$. Refractory periods were measured by the extrastimulus technique with a modified Medtronic pulse generator (5837), delivering a premature beat with a variable coupling interval after every eighth beat of the basic driven cycle. All stimuli were delivered at twice diastolic threshold and a pulse duration of $2 \mathrm{~ms}$. The atrium was driven at increasing rates with steps of 10 beats $/ \mathrm{min}$, beginning with a frequency as close as possible to the spontaneous sinus rate, until a rate of $200 / \mathrm{min}$ was reached or high degree AV block appeared. The mean sinoatrial recovery time was calculated from 5 successive determinations.

TABLE 2 Conduction intervals before and after mexiletine

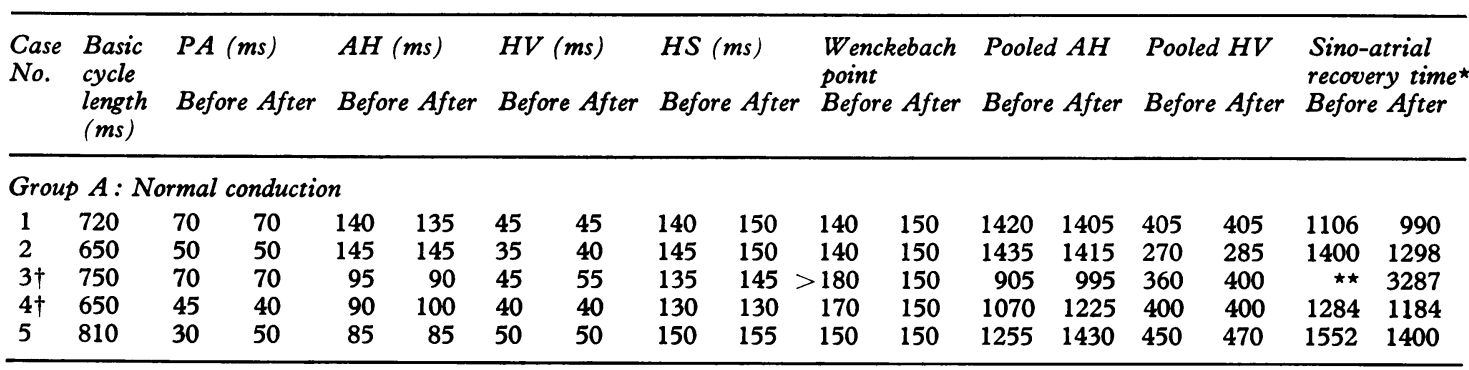

Group B : Infra-His conduction delay

\begin{tabular}{|c|c|c|c|c|c|c|c|c|c|c|c|c|c|c|c|c|c|}
\hline 6 & 900 & 50 & $\star \star$ & 90 & $\star \star$ & 55 & 55 & 225 & 235 & $\star \star$ & $\star \star$ & $\star \star$ & $\star \star$ & $\star \star$ & $\star \star$ & $\star \star$ & $\star \star$ \\
\hline 7 & 750 & 30 & 30 & 90 & 90 & 65 & 65 & 165 & 170 & 130 & 130 & 1150 & 1420 & 520 & 520 & 1030 & 950 \\
\hline 8 & 700 & 20 & $\star \star$ & 120 & $\star \star$ & 65 & 85 & 240 & $\star \star$ & $\star \star$ & $\star \star$ & $\star \star$ & $\star \star$ & $\star \star$ & $\star \star$ & $\star \star$ & $\star \star$ \\
\hline $9 \dagger$ & $260 \ddagger$ & $\star \star$ & $\star \star$ & $\star \star$ & $\star \star$ & 45 & 60 & 145 & 200 & $\star \star$ & $\star \star$ & $\star \star$ & $\star \star$ & $\star \star$ & $\star \star$ & $\star \star$ & $\star \star$ \\
\hline 10 & 720 & 30 & 30 & 80 & 80 & $\sim$ & $\sim$ & $\sim$ & $\sim$ & 140 & 140 & 955 & 985 & - & - & 1146 & 1090 \\
\hline 11 & 700 & 50 & 50 & 80 & 80 & $\frac{60-}{110}$ & $\frac{75-}{130}$ & $\begin{array}{r}180- \\
230\end{array}$ & $\begin{array}{r}190- \\
250\end{array}$ & 170 & 140 & 750 & 745 & 120 & 160 & 998 & 835 \\
\hline $12 \dagger$ & 700 & 40 & 40 & 100 & 100 & 60 & 60 & 140 & 140 & 190 & 160 & 1125 & 1180 & 720 & 780 & 1348 & 1756 \\
\hline 13 & $240 \ddagger$ & $\star \star$ & $\star \star$ & $\star \star$ & $\star \star$ & 60 & 70 & 220 & 230 & $\star \star$ & $\star \star$ & $\star \star$ & $\star \star$ & $\star \star$ & $\star \star$ & $\star \star$ & $\star \star$ \\
\hline 14 & 900 & 35 & 35 & 80 & 80 & 40 & 40 & 160 & 160 & 120 & 120 & 1175 & 1195 & 440 & 440 & 1354 & 1355 \\
\hline 15 & 550 & 30 & 30 & 80 & 80 & 40 & 40 & 150 & $155=$ & $>190$ & $>190$ & 955 & 930 & 360 & 415 & 828 & 762 \\
\hline 16 & 610 & 50 & 50 & 90 & 90 & 60 & 60 & 180 & $185=$ & $>190$ & $>190$ & 1206 & 1245 & 600 & 600 & 886 & 816 \\
\hline $17 \dagger$ & 960 & 50 & $50-90$ & 120 & 115 & 50 & 50 & 150 & 150 & 100 & 100 & 1130 & 1215 & 350 & 350 & 1286 & 1430 \\
\hline 18 & 650 & 50 & 50 & 105 & 115 & 55 & 55 & 130 & 130 & 170 & 150 & 965 & 1130 & 330 & 330 & 1074 & 988 \\
\hline
\end{tabular}

Group C: Supra-His conduction delay

\begin{tabular}{|c|c|c|c|c|c|c|c|c|c|c|c|c|c|c|c|c|c|}
\hline $19 \dagger$ & 750 & $30-50$ & 50 & 160 & 150 & 50 & 50 & 170 & 170 & 120 & 160 & 1490 & 1535 & 400 & 400 & 1474 & 1562 \\
\hline $20 \dagger$ & 830 & 40 & $\star \star$ & 230 & $\star \star$ & 75 & 75 & 235 & 250 & $\star \star$ & $\star \star$ & $\star \star$ & $\star \star$ & $\star \star$ & $\star \star$ & $\star \star$ & $\star \star$ \\
\hline 21 & 750 & 50 & 50 & 190 & 170 & 50 & 50 & 125 & 125 & 100 & 80 & 420 & 460 & 100 & 100 & 1110 & 1302 \\
\hline 22 & 800 & 40 & 40 & $\begin{array}{l}170- \\
255\end{array}$ & $\S^{195-} 205$ & $\S$ & $50 \S$ & $135 \S$ & $145 \S$ & 150 & 140 & & 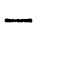 & 一 & 一 & 1286 & 1216 \\
\hline $23 \dagger$ & 700 & 30 & 30 & $\sim$ & $\begin{array}{r}140 \\
250\end{array}$ & 35 & 35 & 110 & 110 & $<80$ & T & T & $\pi$ & 9 & Tा & 4480 & II \\
\hline $\begin{array}{l}24 \dagger \\
25 \dagger\end{array}$ & $\begin{array}{l}680 \\
650\end{array}$ & $\begin{array}{l}\dagger \dagger \\
50\end{array}$ & $\begin{array}{l}\dagger \dagger \\
50\end{array}$ & $\begin{array}{r}\dagger \dagger \\
170\end{array}$ & $\begin{array}{l}550 \\
180\end{array}$ & $\begin{array}{l}50 \\
55\end{array}$ & $\begin{array}{l}60 \\
60\end{array}$ & $\begin{array}{l}140 \\
140\end{array}$ & $\begin{array}{l}150 \\
150\end{array}$ & $\begin{array}{r}+\dagger \\
130\end{array}$ & $\begin{array}{l}110 \\
110\end{array}$ & $\begin{array}{r}\dagger \dagger \\
1055\end{array}$ & $\begin{array}{r}\dagger \dagger \\
1325\end{array}$ & $\begin{array}{r}+t \\
330\end{array}$ & $\begin{array}{r}+\dagger \\
360\end{array}$ & $\begin{array}{r}+\dagger \\
930\end{array}$ & $\begin{array}{r}\dagger \dagger \\
1158\end{array}$ \\
\hline
\end{tabular}

*Mean of 5 determinations.

†Patients with the sick sinus syndrome.

$\ddagger$ Spontaneous atrial cycle length (ms).

$\$ \mathrm{AH}_{2}, \mathrm{H}_{2} \mathrm{~V}$, and $\mathrm{H}_{2} \mathrm{~S}$ intervals in Case 22 with split His bundle deflection (see text)

TNo values because of complete heart block and loss of atrial capture after mexiletine.

$\star \star$ No values because of atrial arrhythmias.

$\dagger+N o$ values because of atrial quiescence and absence of atrial capture.

$\sim$ No values because of complete heart block. 
After completion of control measurements, 200 to $250 \mathrm{mg}$ mexiletine was infused intravenously at a constant rate over a 5 minute period, followed by a maintenance infusion of 60 to $90 \mathrm{mg}$ per hour. The dose each patient received is listed in Table 1. All measurements were repeated and completed within 20 minutes after the beginning of the infusion. One or more venous blood samples were obtained during the study for plasma mexiletine determination by gas-liquid chromatography, using a modification of the method described by Kelly et al. (1973).

\section{Definition of terms}

$P A$ interval: time in $\mathrm{ms}$ between the stimulus artefact and the first sharp deflection of the $\mathbf{P}$ wave on the His bundle electrogram (normal 20 to $50 \mathrm{~ms}$ ).

$A H$ interval : time between the onset of the $\mathrm{P}$ wave on the His bundle electrogram and the onset of the His spike (normal 60 to $140 \mathrm{~ms}$ ).

$H V$ interval: time between the onset of the His spike and the onset of the QRS complex in the standard leads (normal 30 to $55 \mathrm{~ms}$ ).

$H S$ interval: time between the onset of the His spike and the end of the QRS complex in the standard leads (normal 100 to $145 \mathrm{~ms}$ ).

Pooled AH intervals : sum in ms of the $\mathrm{AH}$ times at each driven atrial rate with $1: 1$ or $2: 1 \mathrm{AV}$ conduction.

Pooled HV intervals : sum in ms of the HV intervals of each driven atrial rate with $1: 1$ conduction.

Wenckebach point: the highest driven atrial rate permitting $1: 1$ conduction. In patients with the Wenckebach phenomenon while in sinus rhythm the highest driven atrial rate permitting 2:1 conduction was taken as Wenckebach point.

Sinoatrial recovery time: the interval in ms between the last pacemaker spike and the first spontaneous $P$ wave after abruptly turning off the external pacemaker $20 \mathrm{~s}$ after atrial pacing at a rate of $120 /$ min (normal $954 \pm 196$ (SD) ms).

Effective refractory period of the atrium $\left(E R P_{\mathrm{a}}\right)$ : the longest $S_{1}-S_{2}$ interval at which $S_{2}$ does not propagate into the atrium.

Effective refractory period of the $A V$ node $\left(E R P_{\mathrm{avn}}\right)$ :

TABLE 3 Effects of mexiletine on refractory periods in 17 patients

\begin{tabular}{|c|c|c|c|c|c|c|c|c|c|c|c|}
\hline $\begin{array}{l}\text { Case } \\
\text { No. }\end{array}$ & $\begin{array}{l}\text { Basic cycle } \\
\text { length (ms) }\end{array}$ & $\begin{array}{l}\text { ERPa } \\
\text { Before }\end{array}$ & After & $\begin{array}{l}E R P_{a v} \\
\text { Before }\end{array}$ & ${ }^{n}$ After & $\begin{array}{l}F R P_{a v n} \\
\text { Before }\end{array}$ & After & $\begin{array}{l}R R P_{h p s} \\
\text { Before }\end{array}$ & After & $\begin{array}{l}\text { ERPhps } \\
\text { Before }\end{array}$ & After \\
\hline \multicolumn{12}{|c|}{ Group A: Normal conduction } \\
\hline $\begin{array}{l}1 \\
2 \\
3 \star \\
4^{\star} \\
5\end{array}$ & $\begin{array}{l}720 \\
650 \\
750 \\
650 \\
810\end{array}$ & $\begin{array}{r}<300 \\
230 \\
335 \\
250 \\
295\end{array}$ & $\begin{array}{r}<320 \\
240 \\
350 \\
250 \\
320 \\
\end{array}$ & $\begin{array}{r}340 \\
330 \\
\S \\
300 \\
\leqslant 340 \\
\end{array}$ & $\begin{array}{r}340 \\
315 \\
\S \\
295 \\
\leqslant 370\end{array}$ & $\begin{array}{l}470 \\
460 \\
420 \\
390 \\
475\end{array}$ & $\begin{array}{l}450 \\
465 \\
430 \\
400 \\
485\end{array}$ & $\begin{array}{r}\ddagger \\
\ddagger \\
<420 \\
\ddagger \\
\$\end{array}$ & $\begin{array}{r}\ddagger \\
\vdots \\
480 \\
\ddagger \\
\$\end{array}$ & $\begin{array}{l}\ddagger \\
\ddagger \\
\ddagger \\
\ddagger \\
\ddagger \\
\vdots \\
\$\end{array}$ & $\begin{array}{l}\ddagger \\
\vdots \\
\ddagger \\
\vdots \\
+ \\
\vdots \\
\S\end{array}$ \\
\hline \multicolumn{12}{|c|}{ Group B: Infra-His conduction delay } \\
\hline $\begin{array}{l}10 \\
11 \dagger \\
12^{\star} \\
14 \\
15 \\
16 \\
17^{\star} \\
18 \\
\end{array}$ & $\begin{array}{l}720 \\
700 \\
700 \\
900 \\
550 \\
610 \\
960 \\
650 \\
\end{array}$ & $\begin{array}{r}300 \\
290 \\
260 \\
270 \\
220 \\
\leqslant 230 \\
320 \\
200 \\
\end{array}$ & $\begin{array}{r}270 \\
250 \\
290 \\
270 \\
240 \\
\leqslant 230 \\
360 \\
220 \\
\end{array}$ & $\begin{array}{r}\S \\
<310 \\
315 \\
<340 \\
<240 \\
\leqslant 240 \\
525 \\
275 \\
\end{array}$ & $\begin{array}{r}290 \\
<310 \\
\leqslant 335 \\
330 \\
<250 \\
\leqslant 265 \\
440 \\
280\end{array}$ & $\begin{array}{r}\leqslant 445 \\
\leqslant 420 \\
\leqslant 380 \\
515 \\
330 \\
335 \\
575 \\
370 \\
\end{array}$ & $\begin{array}{r}480 \\
\leqslant 430 \\
\leqslant 410 \\
490 \\
350 \\
335 \\
580 \\
390 \\
\end{array}$ & $\begin{array}{r}\ddagger \\
520 \\
405 \\
\S \\
<330 \\
\S \\
\ddagger \\
390\end{array}$ & $\begin{array}{r}\ddagger \\
680 \\
470 \\
\ddagger \\
550 \\
\S \\
\ddagger \\
520\end{array}$ & $\begin{array}{r}\ddagger \\
+ \\
420 \\
\ddagger \\
\ddagger \\
\S \\
\S \\
\S \\
\vdots \\
\vdots \\
375\end{array}$ & $\begin{array}{r}\ddagger \\
570 \\
\ddagger \\
\ddagger \\
\ddagger \\
\S \\
\S \\
\ddagger \\
475\end{array}$ \\
\hline \multicolumn{12}{|c|}{ Group C: Supra-His conduction delay } \\
\hline $\begin{array}{l}19 \star \\
21 \\
22 \\
23^{\star} \\
25^{\star}\end{array}$ & $\begin{array}{l}750 \\
750 \\
800 \\
700 \\
650\end{array}$ & $\begin{array}{l}270 \\
310 \\
330 \\
360 \\
265\end{array}$ & $\begin{array}{l}300>250 \\
280 \\
310 \\
240\end{array}$ & $\begin{array}{r}0 \quad 440 \\
470 \\
\star \star \\
>750 \\
360 \\
\end{array}$ & $\begin{array}{r}500 \\
475 \\
<340 \\
9 \\
415\end{array}$ & $\begin{array}{r}560 \\
645 \\
\star \star \\
>750 \\
515\end{array}$ & $\begin{array}{r}610 \\
655 \\
\star \star \\
9 \\
580\end{array}$ & $\begin{array}{r}\ddagger \\
\vdots \\
\vdots \\
790 \\
\vdots \\
\vdots \\
+\end{array}$ & $\begin{array}{r}\ddagger \\
\vdots \\
\vdots \\
\star \star \\
\vdots \\
+ \\
+\end{array}$ & $\begin{array}{r}\ddagger \\
\vdots \\
\vdots \\
\geqslant 790 \\
\vdots \\
\vdots\end{array}$ & $\begin{array}{r}+ \\
+ \\
\vdots \\
\star \\
\vdots \\
+ \\
+\end{array}$ \\
\hline
\end{tabular}

$\star$ Patients with the sick sinus syndrome.

$\dagger$ Because of $2: 1$ block distal to $\mathbf{H}$ the actual hps-refractoriness is $>700 \mathrm{~ms}$ (basic paced cycle): the intervals presented were measured only when last beat of basic cycle before extra stimulus was blocked distal to $H$.

$\ddagger$ Study limited by AV nodal refractoriness.

$\S$ Study limited by atrial refractoriness.

TNot performed because of complete AV nodal block and loss of atrial capture.

$\star \star$ Not obtained because of antegrade conduction bypassing the AV node.

Abbreviations as in text: see 'Definition of terms'. 
the longest $A_{1}-A_{2}$ interval at which $A_{2}$ fails to reach the His bundle.

Functional refractory period of the $A V$ node $\left(F R P_{\mathrm{avn}}\right)$ : the shortest interval between $\mathrm{H}_{1}$ and $\mathrm{H}_{2}$, both of which are conducted from the atrium. Effective refractory period of the His-Purkinje system ( $E R P_{\mathrm{hps}}$ ): the longest $\mathrm{H}_{1}-\mathrm{H}_{2}$ interval at which $\mathrm{H}_{2}$ fails to conduct to the ventricles.

Relative refractory period of the His-Purkinje system $\left(R R P_{\mathrm{hps}}\right)$ : the longest $\mathrm{H}_{1}-\mathrm{H}_{2}$ interval at which $\mathrm{H}_{2}$ conducts to the ventricles with a longer HV interval and/or with an aberrant QRS complex.

\section{Results}

In Table 2 conduction intervals during atrial stimulation as close as possible to the spontaneous sinus rate before and after mexiletine are listed, together with the pooled AH intervals, pooled HV intervals, sinoatrial recovery time, and Wenckebach point during atrial pacing.

Table 3 summarizes the effects of mexiletine on the refractoriness of the His-Purkinje system, AV node, and atrium. Measurement of refractoriness was impossible in 1 patient because of atrial flutter and complete AV block, in another patient because of atrial quiescence with absence of atrial electrical activity, and in 4 patients because of atrial arrhythmias. In 1 patient (Case 7) only control values are available because of atrial flutter induced by an extrastimulus.
Interference with the results by the local anaesthesia with $100 \mathrm{mg}$ lignocaine is unlikely, as has been shown earlier (Schwartz et al., 1974; Roos and Dunning, 1975).

\section{Sinus node function}

In 15 patients sinus rate could be measured before, during, and immediately after the infusion of mexiletine.

The mean rate before mexiletine was $73 \cdot 1 \pm 13 \cdot 0$ (SD) and after mexiletine $75 \cdot 3 \pm 12 \cdot 4$. This difference has no statistical significance. Atrial refractoriness (Fig. 1, Table 3) was not consistently affected by mexiletine. In 6 patients a mean increase of $24 \mathrm{~ms}$ occurred, in 2 patients there was no change, and in 6 patients atrial refractoriness decreased by a mean of $25 \mathrm{~ms}$. The mean net change in all patients was $-0.35 \mathrm{~ms}$ (not statistically significant).

The sinoatrial recovery time is an indicator of sinus node function and was recorded before and after mexiletine in 17 patients (Table 2). In 5 patients it increased (significantly in 1) and in 11 patients it decreased (significantly in 4). The mean sinoatrial recovery time before and after mexiletine was exactly the same (1181 $\mathrm{ms} \pm 211$ and $1181 \pm 274$ $\mathrm{ms}$, respectively). Of the 5 patients who showed an increase after mexiletine, 3 had the sick sinus syndrome, and in only 1 patient with this syndrome did mexiletine decrease the sinoatrial recovery time.

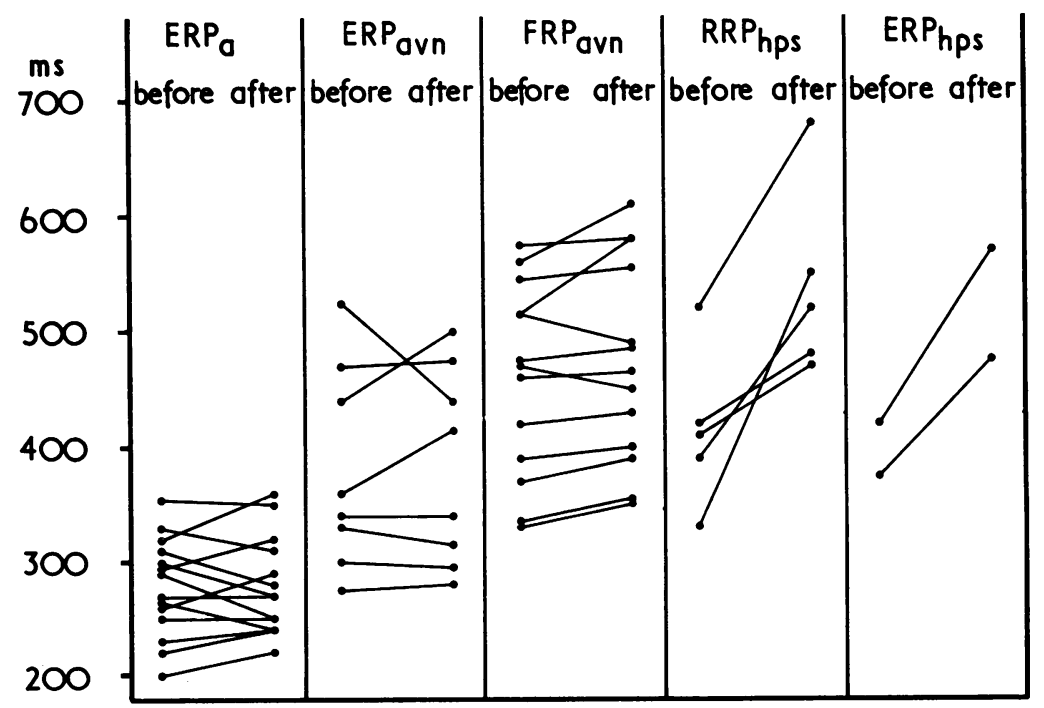

FIG. 1 Refractory periods of the atrium, AV node, and His-Purkinje system before and after intravenous mexiletine. Abbreviations as in text: see 'Definition of terms'. 


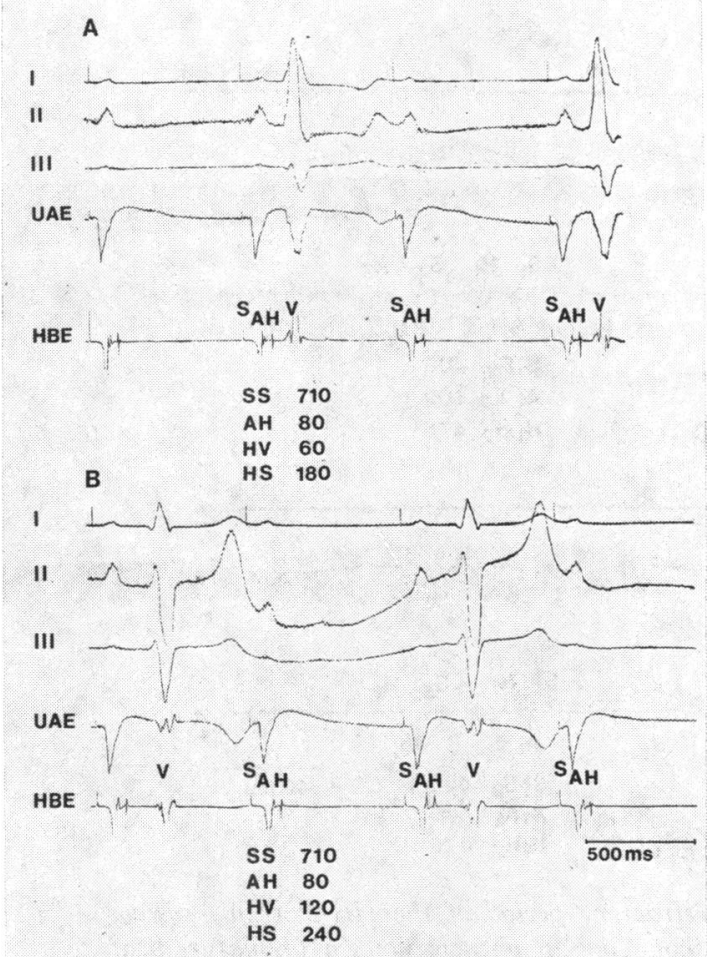

FIG. 2 Case 11. Panel $A$ shows a paced atrial rate (cycle length $710 \mathrm{~ms}$ ) with 2:1 HV block before mexiletine. The conducted beats show complete left bundle-branch block with a HV interval of $60 \mathrm{~ms}$. Panel $B$ shows the same paced atrial rate after intravenous mexiletine. Again 2:1 HV block is present, but now right bundle-branch block with left anterior hemiblock is present, with considerable prolongation of the HV interval to $120 \mathrm{~ms}$ in the conducted beats. $I, I I, I I I$ : standard limb leads; $A$ : atrial wave; $A H$ : $A H$ interval (ms); $H$ : His bundle deflection; $H B E$ : His bundle electrogram; $H S$ : total intraventricular conduction (ms); HV:HV interval (ms); $S$ : stimulus artefact; $S S$ : interval between two atrial stimuli (ms); UAE: unipolar atrial electrogram.

\section{AV nodal conduction}

The AH interval, as measured during atrial pacing at a rate as close as possible to the spontaneous sinus frequency (Table 2) decreased in 5 patients (mean $-9 \mathrm{~ms}$ ), increased in 3 (mean $+10 \mathrm{~ms}$ ), and was unchanged in 8 . The mean net change was $-0.3 \mathrm{~ms}$ (not statistically significant). During atrial pacing, however, at increasing rates, the $\mathrm{AH}$ interval tended to become more prolonged after mexiletine. Thus, the pooled AH intervals (Table 2) increased in 12 patients, though in 5 patients a slight decrease was observed. The mean change after mexiletine was +8 per cent. In 3 patients the Wenckebach point occurred at a higher atrial rate, in 5 patients it remained unchanged, and in 8 patients it was reached at a lower paced atrial rate (Table 2).

The effective refractory period of the AV node was not consistently influenced by mexiletine (Table 3, Fig. 1). In 4 patients the change was $5 \mathrm{~ms}$ or less, in 2 patients the ERP increased (mean $50 \mathrm{~ms}$ ) and in 2 others it decreased (mean $57 \mathrm{~ms}$ ). The mean net change was $+2.5 \mathrm{~ms}$ (not statistically significant). The functional refractory period of the AV node increased more consistently in 11 patients (mean $+21.8 \mathrm{~ms}$ ) and decreased in 2 (mean -22.5 ms); the mean net change was $+14 \cdot 2 \mathrm{~ms}$, but was not statistically significant.

\section{His-Purkinje conduction}

Of the 5 patients with normal conduction, 2 showed a minimal increase of the HV interval after mexiletine $(+5$ and $+10 \mathrm{~ms})$. One of these also showed a slight increase of the relative refractory period of the His-Purkinje system (Table 3). Six other patients showed an increase of the HV conduction time. Four of these had infra-His conduction defects (mean increase $+15 \mathrm{~ms}$ ) and 2 supra-His conduction delay (mean increase $+7.5 \mathrm{~ms}$ ) (Table 2). The mean increase of the HV interval was $3.3 \mathrm{~ms}$, which was not statistically significant. In the 5 patients in whom the relative refractory period of the His-Purkinje system could be measured, a consistent and statistically significant increase (mean $+127 \mathrm{~ms}, \mathrm{P}<0.05$ ) was found after mexiletine. Four of these patients had infra-His conduction disturbances. In 2 patients (also with conduction delay below the His bundle) the effective refractory period of the His-Purkinje system increased (mean $+125 \mathrm{~ms}$ ). Some of the electrophysiological responses of these patients to mexiletine are illustrated in Fig. 2 and 3. Fig. 4 shows the effects of mexiletine on an antegrade AV nodal bypass tract in a patient with an intra-His conduction defect; the effective refractory period of this tract increased from 340 to $680 \mathrm{~ms}$ after mexiletine.

\section{Complete heart block}

Of the 3 patients with complete heart block, the effects of mexiletine could be assessed in 2 , the third being completely pacemaker dependent. In Case 13, who had complete AV nodal block, the frequency of the AV junctional escape rhythm was not changed by mexiletine. The second patient (Case 23), also with complete AV nodal block, had a period of 


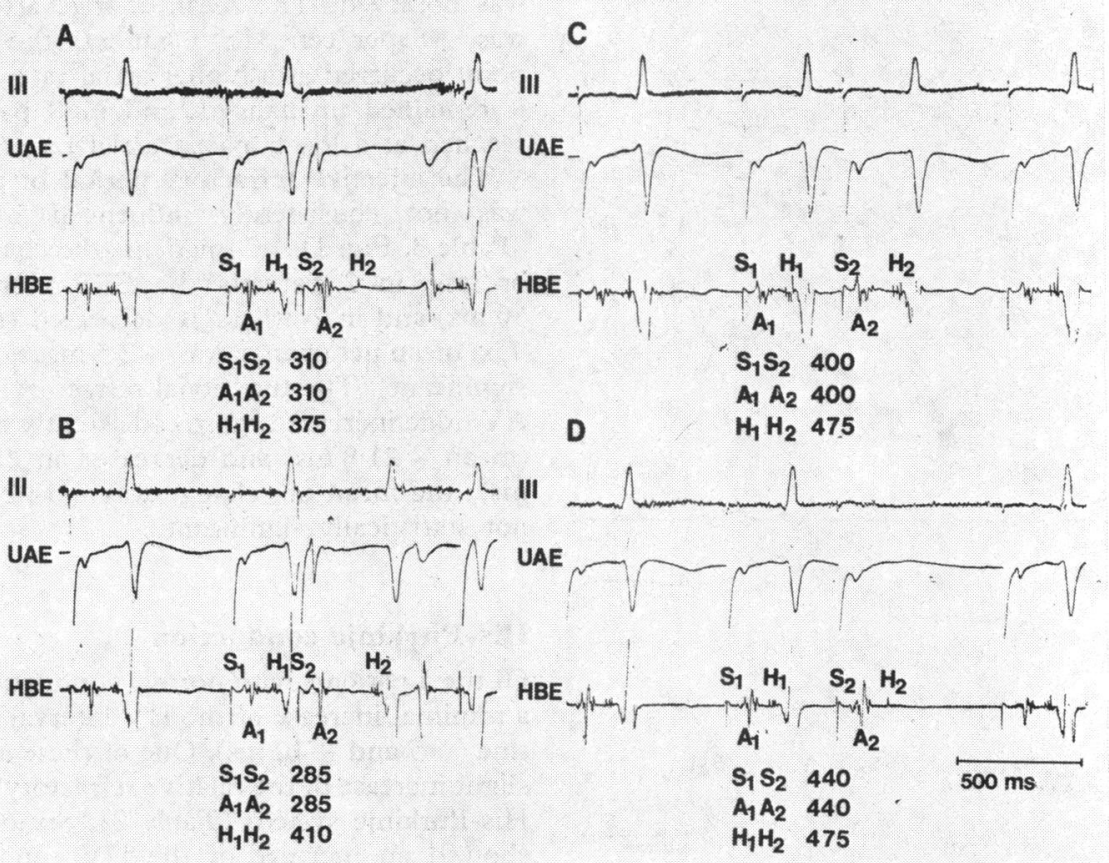

FIG. 3 Case 18. Panel $A$ shows the effective refractory period of the His-Purkinje system ( $\mathrm{H} 1-\mathrm{H} 2=375 \mathrm{~ms}$ ) before mexiletine. Panel $B$ shows a gap phenomenon: a premature beat with a shorter coupling interval than in panel $A(285 \mathrm{~ms})$ is now conducted to the ventricles because the H1-H2 interval increases to $410 \mathrm{~ms}$ because of functional AV nodal refractoriness. Panel $D$ shows an increased effective refractory period of the His-Purkinje system (475 ms) after intravenous mexiletine. Panel $C$ shows that before mexiletine a premature beat with the same H1-H2 interval of $475 \mathrm{~ms}$ is conducted to the ventricles. The basic cycle length in all panels is $650 \mathrm{~ms}$. The His bundle deflection is fragmented, showing 3 separate spikes in all conducted beats; the blocked beats show only 1 spike, indicating intra-His conduction disturbance. Abbreviations and symbols as in Fig. 2.

FIG. 4 Case 22. Panel $A$ shows a paced atrial rhythm with a cycle length of $500 \mathrm{~ms}$ before mexiletine. There is apparent 2:1 AV nodal block; however, when the cycle was shortened to a critical length of $400 \mathrm{~ms}$ (not shown in figure) a split His bundle deflection ( $H^{1}$ and $H^{2}$ ) appeared with a stable $A H^{1}$ interval of $160 \mathrm{~ms}$, indicating normal $A V$ nodal conduction and 2:1 intra-His block; apparently an $A V$ nodal bypass tract existed (Fames bundle) which became refractory at a critical cycle length of $400 \mathrm{~ms}$. Panel $B$ shows the same cycle length of $500 \mathrm{~ms}$ after intravenous mexiletine. Because of refractoriness of the $A V$ nodal bypass tract, conduction takes place through the AV node, unmasking a 2:1 intra-His block (every second beat being blocked distal to $H^{1}$ ), with a normal $A H^{1}$ interval at this rate of $140 \mathrm{~ms}$. Abbreviations and symbols as in Fig. 2.

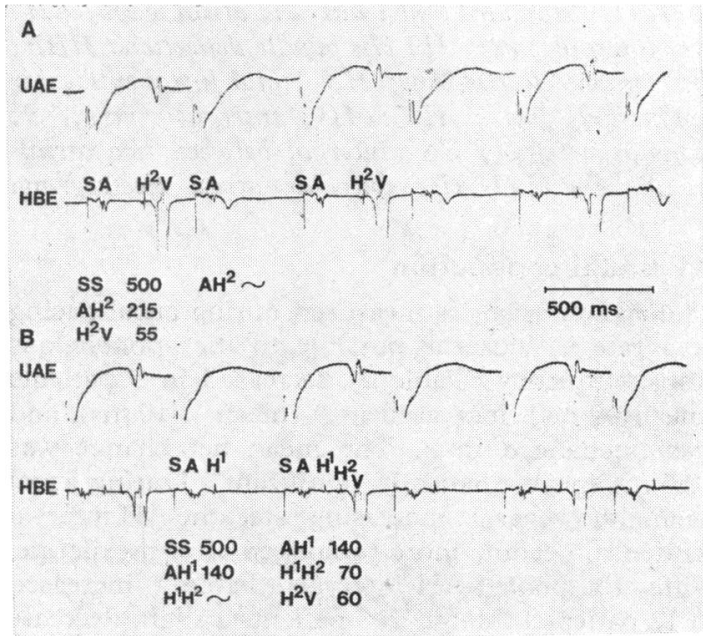


$14 \mathrm{~s}$ total cardiac standstill after mexiletine; this patient is described in greater detail below.

\section{Plasma mexiletine levels}

Eighteen patients received an intravenous loading dose of $250 \mathrm{mg}$ mexiletine in 5 minutes, followed by a continuous infusion of 60 to $90 \mathrm{mg}$ per hour. The plasma levels at the time of study ranged from 0.46 to $6.2 \mu \mathrm{g} / \mathrm{ml}$ (mean $1.65 \pm 0.40($ SEM)). Six patients received a loading dose of $200 \mathrm{mg}$ in 5 minutes, followed by a maintenance infusion of $60 \mathrm{mg}$ per hour. The plasma levels ranged from 0.28 to $1.15 \mu \mathrm{g} / \mathrm{ml}$ (mean $0.83 \pm 0.14$ ). Therapeutic plasma levels range from 0.5 to $2.0 \mu \mathrm{g} / \mathrm{ml}$ (Talbot et al., 1973). Two of our patients had plasma levels less than $0.5 \mu \mathrm{g} / \mathrm{ml}$, and 2 had toxic levels (>3 $\mu \mathrm{g} / \mathrm{ml})$; all other patients had plasma levels within the therapeutic range.

\section{Side effects}

Eight patients suffered from side effects; 7 of them had received the higher loading dose of $250 \mathrm{mg}$ in 5 minutes. Nausea was the most frequent symptom ( 6 out of 8 patients), followed by dizziness (3/8), vomiting (3/8), and visual disturbances $(3 / 8)$, namely nystagmus, diplopia, and blurred vision. This high frequency of side effects is related to the dose and the rapidity with which the drug was in-

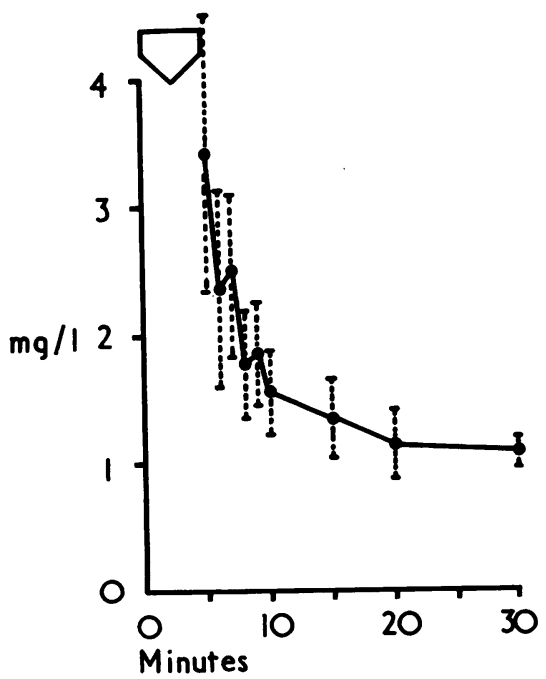

FIG. 5 This figure shows the mean plasma mexiletine levels ( $\pm S E M$ ) in 5 patients receiving $250 \mathrm{mg}$ intravenously in 5 minutes, followed by a maintenance infusion of $90 \mathrm{mg} /$ hour. Note that immediately after completion of the injection the plasma level is in the toxic range $(>3 \mu \mathrm{g} / \mathrm{ml})$. jected. Fig. 5 shows that when $250 \mathrm{mg}$ mexiletine is injected in 5 minutes, the plasma level immediately after completion of the injection is above the upper therapeutic limit and clearly in the toxic range. During the next minutes the plasma levels rapidly come down to within the therapeutic range.

One patient (Case 23) had serious cardiac side effects. This patient was studied 48 hours after the onset of symptoms of acute inferior myocardial infarction, complicated by complete AV nodal block, with periods of sinus arrest and AV junctional escape rhythm. At the time of study complete heart block was present. During injection of mexiletine a Wenckebach type of block in the AV node developed, suggesting improved AV nodal conduction. Six and a half minutes after the beginning of the injection there was sudden cardiac standstill lasting for a period of 14 seconds, followed by a ventricular escape beat. Right ventricular pacing was then instituted and after 8 minutes the $P$ waves returned. The plasma level at the time of this event was only $0.46 \mu \mathrm{g} / \mathrm{ml}$, which is no more than the lower limit of the therapeutic range. Though this may have been coincidence, the sequence of events suggests that the injection of mexiletine was responsible for asystole in this case. Another patient (Case 12) with 3:2 sinoatrial block showed a reduction in the number of sinus beats from an average of 73 beats $/ \mathrm{min}$ before to 40 beats $/ \mathrm{min}$ 30 minutes after mexiletine, with periods of sinus arrest up to 3 seconds.

\section{Discussion}

An ideal antiarrhythmic drug, that is effective, easy to administer, and without side effects and toxic reactions has not yet been produced. Lignocaine, probably the least toxic and certainly the most widely used drug in the coronary care unit, is not always effective and should be used cautiously in patients with distal conduction defects (Roos and Dunning, 1975); and it cannot be given orally. Procainamide, quinidine, phenytoin, and $\beta$-adrenergic blocking drugs, all of which can be administered orally, have more side effects than lignocaine, and especially in the long-term treatment of arrhythmias the incidence of adverse reactions is high. There is, therefore, a need for additions to our therapeutic armamentarium.

Mexiletine, originally developed as an anticonvulsant drug, has been studied in animals and in a limited number of patients. In animals (Allen et al., 1972; Singh and Williams, 1972) mexiletine was effective in ventricular arrhythmias and especially in those provoked by ouabain. In the isolated rabbit atrium mexiletine reduced the maximum 
frequency with which the atrium could be driven, raised the threshold for electrical stimulation, slowed conduction velocity, and depressed contraction. The drug reduced the maximum rate of rise of the action potential of rabbit atrial and ventricular muscle. The resting potential and action potential duration were not affected.

In the clinical studies of Campbell et al. (1973), Talbot et al. (1973), Campbell et al. (1975), and Achuff et al. (1975), mexiletine appeared to be effective against ventricular arrhythmias, both after acute myocardial infarction and in patients with chronic arrhythmias. When lignocaine failed, mexiletine was often successful. After intravenous administration a high percentage of patients had unacceptable side effects. On the other hand, mexiletine, when given orally, compared favourably with procainamide with respect to toxicity and was equally effective (Campbell et al., 1975).

In this study, designed to analyse the electrophysiological properties of mexiletine, we did not find consistent effects on the spontaneous sinus rate at therapeutic plasma levels. Small and inconsistent changes in both directions of atrial refractoriness were found and the same was true for sinoatrial recovery times. No appreciable changes were found in atrial conduction time. Two patients, however, showed a striking reduction or even total absence of sinus activity after mexiletine. Both had pre-existent sinus node dysfunction. In animal experiments, mexiletine has been shown to cause sinus bradycardia, and bradyarrhythmias were described in man as a side effect (Campbell et al., 1973; Talbot et al., 1973). A possible explanation for the fact that sinus node function was not influenced by mexiletine in 23 of the 25 patients studied, could be that the drug has both a vagolytic activity and an intrinsic depressant effect. Such effects work in opposite directions and the net result depends on which of the two is stronger in an individual patient. Patients with sinus node dysfunction are known to respond to atropine-like drugs with only minimal increase in sinus frequency, and it is plausible that in these patients a depressant effect of mexiletine would become manifest.

Conduction time through the AV node was not influenced by mexiletine at driven atrial rates close to the spontaneous sinus rate. However, at higher frequencies the pooled AH times tended to increase and the Wenckebach point shifted to a lower atrial rate in the majority of the patients. The effective refractory period of the AV node changed only slightly, and in both directions, while AV nodal functional refractoriness increased. Measurements of the three variables reflecting AV nodal conduction (functional refractory period, Wenckebach point, and pooled $\mathrm{AH}$ intervals) were available in 14 patients before and after mexiletine. In 11 out of these 14 patients, 2 or 3 of these measurements indicated depressed conduction after mexiletine; in 2 patients the Wenckebach point was unchanged, while the 2 other variables changed in opposite directions; in only 1 patient did all 3 measurements indicate improved conduction. The exact mechanism by which mexiletine influences AV nodal function is not clear. The net effect in the majority of patients, both with normal and abnormal AV nodal conduction, is decreased conduction. Again this may be the resultant of a vagolytic and an (in most of the patients apparently dominating) intrinsic depressant action. In Case 23 the sequence of events (improved AV nodal conduction followed by cardiac standstill) is consistent with the view that mexiletine has such a dual action. The net effect of mexiletine on AV nodal conduction could be of value in the treatment of re-entrant tachycardias involving the AV node. Its possible usefulness in tachycardias associated with pre-excitation is illustrated by one patient in our study (Fig. 5). Two patients in this study, with atrial tachycardias occurring during catheterization, reverted to sinus rhythm after mexiletine; another patient, not in this study, with paroxysmal supraventricular tachycardia, resistant to all conventional drugs, has now been free of attacks for $1 \frac{1}{2}$ years on treatment with oral mexiletine.

In this study mexiletine appeared to produce a small increase in total intraventricular conduction time in the majority of the patients. In some patients (most of them with pre-existing infra-His conduction defects) the $\mathrm{HV}$ interval increased and/or His-Purkinje refractoriness increased. These results are in agreement with those of Lang, Just, and Limbourg (1975), who also found delayed infra-His conduction in some of their patients. In this respect, mexiletine resembles procainamide (Josephson et al., 1974a) and quinidine (Josephson et al., 1974b) and should be classified as a class IA antiarrhythmic drug (Singh and Hanswirth, 1974). McComish et al. (1975), however, found, in patients with normal cardiac conduction, a slight but statistically significant decrease of the relative refractory period of the His-Purkinje system after mexiletine.

The mechanism by which mexiletine exerts its antiarrhythmic effect thus seems to be a complicated one. It seems likely that mexiletine, like lignocaine, acts differently on normal and diseased conduction tissue.

Like Campbell et al. (1973) and Talbot et al. (1973) we found a high incidence of side effects after intravenous injection of mexiletine (8 out of 25 patients). Two patients had a cardiotoxic reaction which was severe in one of these. Seven of the 8 
patients who suffered from side effects had received the higher dose of $250 \mathrm{mg}$ infused over 5 minutes, while only 1 patient, who received $200 \mathrm{mg}$ in 5 minutes, showed mild symptoms (diplopia). The side effects were thus related to the dose and the rapidity of intravenous injection and were confined to a period of 5 to 20 minutes after the loading dose was given.

Like Talbot et al. (1973) our experience with oral mexiletine indicates that side effects do not occur or only rarely do so with this route of administration. The apparent effects on intracardiac conduction and the described adverse effects in 2 patients make the drug less suitable for treatment of patients with pre-existing disturbances of impulse formation and/or infra-His conduction.

We thank Mr. J. Siebeling of Boehringer Ingelheim for providing the mexiletine.

\section{References}

Achuff, S. C., Campbell, R. W. F., Pottage, A., Murray, A., Prescott, L., and Julian, D. G. (1975). Mexiletine in the prevention of ventricular dysrhythmias in acute myocardial infarction. Circulation, 52, Suppl. II, 147.

Allen, J. D., Kofi Ekue, J. M., Shanks, R. G., and Zaidi, S. A. (1972). The effect of Kö 1173, a new anticonvulsant agent on experimental cardiac arrhythmias. British fournal of Pharmacology, 45, 561.

Campbell, N. P. S., Chaturvedi, N. C., Kelly, J. G., Strong, J. E., Shanks, R. G., and Pantridge, J. F. (1973). Mexiletine (Kö 1173) in the management of ventricular dysrhythmias. Lancet, $2,404$.

Campbell, R. W. F., Talbot, R. G., Dolder, M. A., Murray, A., Prescott, L. F., and Julian, D. G. (1975). Comparison of procainamide and mexiletine in prevention of ventricular arrhythmias after acute myocardial infarction. Lancet, 1, 1257.

Josephson, M. E., Caracta, A. R., Ricciutti, M. A., Lau, S. H., and Damato, A. N. (1974a). Electrophysiologic properties of procainamide in man. American fournal of Cardiology, 33, 596.
Josephson, M. E., Seides, S. F., Batsford, W. P., Weisfogel, G. M., Akhtar, M., Caracta, A. R., Lau, S. H., and Damato, A. N. (1974b). The electrophysiological effects of intramuscular quinidine on the atrioventricular conduction system in man. American Heart fournal, 87, 55.

Kelly, J. G., Nimmo, J., Rae, R., Shanks, R. G., and Prescott, L. F. (1973). Spectrophotofluorometric and gas-liquid chromatographic methods for the estimation of mexiletine (Kö 1173) in plasma and urine. Fournal of Pharmacy and Pharmacology, 25, 550.

Lang, K. F., Just, H., and Limbourg, P. (1975). Untersuchungen über die Einwirkung von Mexiletin (Kö 1173) auf die AV-Überleitungszeit und Sinusimpulsautomatie bei Herzgesunden und Patienten mit Erkrankung des Reizleitungssystems. Zeitschrift für Kardiologie, 64, 389. McComish, M., Crook, B., Kitson, D., and Jewitt, D. (1975). Clinical electrophysiological effects of mexiletine, a new local anaesthetic type of anti-arrhythmic drug. Circulation, 52, Suppl. II, 215.

Roos, J. C., and Dunning, A. J. (1975). Effects of lidocaine on impulse formation and conduction defects in man. American Heart fournal, 89, 686.

Scherlag, B. J., Lau, S. H., Helfant, R. H., Berkowitz, W. D., Stein, E., and Damato, A. N. (1969). Catheter technique for recording His bundle activity in man. Circulation, 39, 13.

Schwartz, M. L., Covino, B. G., Narang, R. M., Sethi, V., Tholpady, S. S., Kuangparichat, M., Giordano, C., and Meyer, M. B. (1974). Blood levels of lidocaine following subcutaneous administration prior to cardiac catheterization. American Heart fournal, 88, 72.

Singh, B. N., and Hauswirth, O. (1974). Comparative mechanisms of action of antiarrhythmic drugs. American Heart Fournal, 87, 367.

Singh, B. N., and Williams, E. M. V. (1972). Investigations of the mode of action of a new anti-dysrhythmic drug, Kö 1173. British Fournal of Pharmacology, 44, 1.

Talbot, R. G. (1975). Mexiletine (annotation). American Heart fournal, 89, 537.

Talbot, R. G., Clark, R. A., Nimmo, J., Neilson, J. M. M., Julian, D. G., and Prescott, L. F. (1973). Treatment of ventricular arrhythmias with Mexiletine (Kö1173). Lancet, 2, 399.

Requests for reprints to Dr. Julius C. Roos, Section of Cardiology, Binnengasthuis, 10 Grimburgwal, Amsterdam, The Netherlands. 